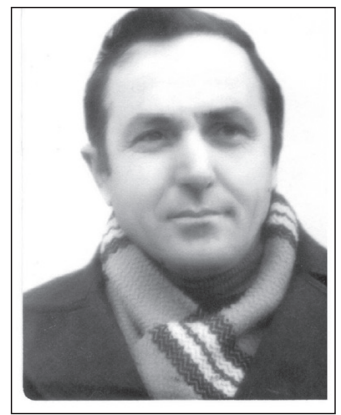

\title{
Qëmtime rreth veprës së pabotuar të autorit elbasanas Shpëtim Karaj
}

\section{Valbona Kalo}

\author{
"Vargjet tua janë për t’i lexue në heshtje \\ e jo para mikrofonit \\ si të çetës së poetëve tjerë."
}

Për të gjithë shkrimtarët ekziston një marrëdhënie ndërvarësie e pandërprerë mes mjedisit gjeografik, social, letrar e kulturor dhe botëkuptimit e origjinalitetit të shprehjes, si faktorët përcaktues që i shërbejnë krijimit të një individualiteti të spikatur artistik.

Nën dritën e një raporti të tillë duhet parë edhe vepra e autorit elbasanas Shpëtim Karaj, shtrirja dhe shkallarja e cilësisë të së cilës ka ardhur gjithnjë në rritje, që nga sprovat e para poetike të autorit (në vitet 1955-'60) e deri në ato të fundit, që i përkasin viteve 2005.

Vepra e këtij autori vjen nga një përvojë modeste botimi para dhe pas viteve '90, përmes të cilës ai bëhet i njohur kryesisht si;

- skenarist i filmit “Shokët”, 1982, prodhim i Kinostudios Shqipëria e Re, shfaqur më 1983 dhe përkthyes nga gjuha frënge i disa veprave si:

- romanit "Pagesa e frikës", e autorit, Zhorzh Arno, më 1983,

- dramës me tri akte "Vrasës pa shpërblim: Mbreti po vdes"të autorit Eugen Ionesco, Shtëpia Botuese "Onufri, 1994,

- romanit "Planetarium" të autores Nathali Sarraut, më 1995.

1 Martin Camaj, poezia "Nji poeti të sotëm" 
Por, për fat të keq, ky autor elbasanas (emri i të cilit në mjedisin kulturor të këtij qyteti lidhet ngushtë me bibliotekën "Qemal Baholli”, ku ka drejtuar me profesionalizëm dhe ka organizuar me pasion punën shkencore me librin nga viti 1972-'76) ${ }^{2}$ mbetet ende i panjohur në fushën e krijimtarisë letrare, në dy prej zhanreve kryesore të së cilës, ka lënë disa vepra në dorëshkrim:

Në poezi: vëllimet poetike "Dijetari $i$ humbur" dhe "Kënga e vërtetë e Rexhës"

\section{Në prozë: romanet “Tersi i pojanit" dhe "Satanai"}

Një kontribut të rëndësishëm në fushën e leksikografisë përbën gjithashtu përpjekja dhe puna sistematike e autorit në harkun kohor prej 30 viteve, për hartimin e një fjalori shqip-shqip, si dhe bibliografia në gjuhë të huaj kushtuar figurës historike së Ali Pashë Tepelenës.

Objekt i këtij shkrimi do të jetë vetëm një prej veprave të krijimtarisë letrare të autorit: përmbledhja poetike “Dijetari $\boldsymbol{i}$ humbur”, e cila është tashmë në proces botimi, si vepër postume.

Eksperienca e leximit dhe qëmtimi i përimëtuar i poezive të kësaj përmbledhjeje na shpie drejt pohimit se ajo duhet parë e trajtuar si një projekt me vlera të mirëfillta artistike që, nga njëra anë, pasqyron shpirtin dhe dramën ekzistenciale të vetë autorit por nga ana tjetër, shpreh edhe një refuzim estetik të modeleve të kornizuara nga dogma e realizmit socialist (nga ndikimi i të cilave, autori nuk mundi të shpëtonte, për fat të keq, në skenarin e filmit "Shokët").

Përmbledhja poetike 'Dijetari $i$ humbur' e autorit Shpëtim Karaj dëshmon për një poezi lirike të karakterit meditativ, plot ndjenja, thellësi mendimi dhe kujtime të subjektit poetik, ku qartësia kuptimore karakteristike për poezinë klasike ia ka lënë vendin tërësisht poezisë filozofike e moderne.

Spontaniteti i vargut me imazhe shpirtërore, që materializohen në elemente e detaje të natyrës së vendlindjes, fryma metafizike, mistike, karakteristike për poetët francezë të gjysmës parë të shekullit XX si Paul Claudel ${ }^{3}$, Saint

2 Biblioteka Publike 'Qemal Baholli" dhe historia e saj, përgatitur nga Drita H. Cankja, Manjola Hatellari, Onufri, Tiranë, 2014, f. 60

3 Ilia Lëngu, Vështrimi i Orfeut, artikuj dhe studime, Argeta-LMG, Tiranë 2007, 41

P.Claudel-përfaqësues i shquar i poezisë franceze me drejtim fetar në gjysmën e parë të shekullit XX.Përballë një bote ku gjithçka dukej sikur është vënë në pikëpyetje ose ishte shpërfytyruar, besimi fetar mbetej një burim i pashtershëm rigjenerimi shpirtëror dhe moral.Claudel mbahet edhe si një nga mjeshtrat e versetit, të cilit i dha ritëm, zhdërvjelltësi, frymëmarrje dhe harmoni të habitshme. 
John Pers, apo Pol Elyar, ${ }^{4}$ vertikalja artistike me vështrimin e subjektivitetit të tij shpirtëror dhe me një përmasë tejet lirike si dhe teknika e veçantë e strukturimi të poezive të ftojnë t’u qasesh vlerave origjinale të tyre.

Po t’i vështrojmë 99 poezitë e vëllimit poetik (autori i quan poema, sipas përdorimit modern të këtij termi - ku përfshihen dhe krijime më të shkurtra me karakter lirik dhe muzikalitet ${ }^{5}$ ), të bie në sy përnjëherë "surpriza" e emërtimit apo titujt-strukturimi i të cilëve realizon një përftesë (teknikë) origjinale që sugjeron shikimin e çdo krijimi të shkurtër lirik si pjesë e një të tëre dhe që krijon një ide dyfishe: e gjatë dhe e shkurtër njëkohësisht, fragment i një të tëre që krijon mëvetësinë e saj semantike dhe artistike brenda njësisë. Efekti artistik realizohet gjithashtu nëpërmjet mungesës së lidhjes leksikore mes titujve me domethënien horizontale të poezive. Kështu, ndërsa titulli kumton apo sugjeron një kuptim, procesi i leximit sugjeron një nëntekst tjetër. Në ilustrim të kësaj ideje mjafton t’i referohemi poezisë

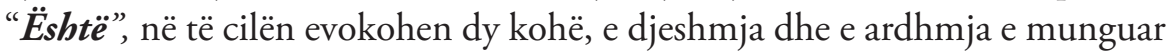
ndërsa e tashmja (është), e kumtuar në titull, qëndron pezull në mes tyre. Krijimi në fjalë është një poezi e konceptuar artistikisht mbi atë që studiuesi I. Rugova e quan: "figurë-refleksion", e cila "vetëm sugjeron një situatë të ekzistimit.”'Metafora funksionalizohet në brendësi të saj (dhe gjithë vëllimit poetik) si njësia bazë e gjuhës mbi të cilën ngrihen të gjitha njësitë semantike të përçimit të asociacioneve që krijohen, ndjenjave që përcillen, imazheve që formësohen.

4 Theksojmë se autori, si njohës i shkëlqyer i gjuhës frënge dhe jo vetëm, i ka lexuar këto poetë në gjuhën origjinale, pra në gjuhën frënge e madje ka përkthyer disa prej poezive të tyre.

5 Dizionare della letteratura, Garzanti, 'La Tipografia Varese S.P.A.", 2003, p 819 Me termin letrar poemë përkufizohet një kompozim letrar në vargje, për më gjërë, i karakterit narrativ apo didaskalik dhe me një shtrirje të gjërë, që shpesh ndahet në pjesë.Përdorimi i këtij lloj termi në kohët moderne dhe duke përshtatur theksin e gjuhës franceze ndonjëherë gjendet edhe në krijime më të shkurtra dhe me karakter lirik si dhe mund të lidhet me një kompozim muzikor.

6 Ibrahim Rugova, Strategjia e kuptimit, Sht. Bot. "F. Konica," Prishtinë, 2005, fq. 208 


\section{Është}

Pikërronin pikë-pikë gulçet e shiut në pëllëmbën time.

Çdo pikël një fat.

Një jetë mes hijeve e dritës,

mes baltës e gjakut.

Në gojën e pikës së shiut

në pëllëmbën time, ishte strukur bota,

përlotej qielli,

Dje dhe nesër qenë tretur aty.

Dje - nuk kishte vdekur.

Nesër-s'do lindë kurrë.

Në një pikël shiu-bota dhe qielli.

Në brendësi të cikleve dhe nëndarjeve të tjera të këtij vëllimi poetik mund të konstatojmë dhe parimet ideoestetike që e përshkrojnë atë. Në radhë të pare prej vetë titujve që shenjojnë pesë përmbledhjet poetike:

\section{Parathënie}

\section{Përmbledhja I- Bota dhe njerëzit}

kreu 1- Koha dhe hapësira

kreu 2- Bota

kreu 3- Njerëzit..

kreu 6 -Vdekja

kreu 7- Djalli

\section{Përmbledhja II- Shilarthi hënës}

Përmbledhja III- Vegime

\section{Përmbledhja IV- Fundbota (poemë në tri pjesë)}

\section{Përmbledhja V-Tri herë i ringjallur}

\section{Përmbyllja}

Dhe nëse më pas i referohemi titujve të vetë poemave, si psh: Nuk e dija, Etja, Ku shkojmë, Sytë e qingjit, Është, Ditë e shpulpuar, Të çmendurit po këndojnë, Dijetari humbur, Shkallët e britmës etj... prej brendisë dhe strukturës së përgjithshme artistike të tyre, prezantohet një botë poetike, që realizon fluturimin në hapësirat e pamata të shpirtit që e drejton mrekullia e intuitës, nostalgjia e fëminisë së ikur, dëshira e pafajshme e qetësisë së përjetshme, liria e të shprehurit të fjalës ZOT gjithmonë dhe kudo, ku nuk mund të lejohet, shija e së ndaluarës së shenjtë, vraga e lotit, ftohtësia e varrit, fryma e nënës e plot motive lirike, që krijojnë një mozaik pa figura të qarta e të 
rregullta, që rimerren apo shtohen me imazhe të mjegullta ëndrre poetike, boshti i së cilave rrotullohet rreth koncepteve ZOT, HAPËSIRË, SHPIRT. Vetë poema e fundit me numur 99 e përforcon idenë e konceptit mistik si frymë e pandarë e të gjithë vëllimit, duke lënë të hapur vazhdimin e mendimit, "po deri ku?" A mund të ketë 100, apo kjo plotësi i përket vetëm Zotit, Allahut, (titulli ifundit "Allahu Ekber")

Lidhja e copëzave si pjesë e së tërës në mënyrë jokronologjike, është një tjetër tregues interesant i kësaj vepre poetike. Autori ka synuar strukturimin sipas rendit llogjik, duke kapërcyer vitet për t'u rikthyer në kohë, si të kishte lënë pas diçka që ai s'do ta harrojë. Gjithsesi, uni poetik vazhdon e plotësohet pa u fragmentarizuar nga faktori kohë. Madje, impresioni që të krijon është ai i mosnjohjes (më saktë i mospranimit) së realitetit të zymtë e fatalist të para viteve '90. Përdorimi i dendur i falorit fetar, si një tjetër karakteristikë leksikore me funksion poetik në vepër, e fuqizon dukshëm rrafshin shpirtëror mistik. Nga ana tjetër, një lexim i vëmendshëm vertikal i veprës do të sugjeronte interpretime më të thella, me shenjues simbolistë.

Në pjesën më të madhe të poemave kemi një përjetim të unit lirik, që aktualizon funksionin gjuhësor të ekzistencës së fjalës në një rrafsh përgjithësues, ku vetë ai (uni lirik) i përket shtresëzimit të peizazhit dhe ku artikulohet raporti i përjetimit të brendshëm poetik të dukurive frymëzuese për poetin.

Poezia "Hambarët e shpirtit" (1992) vizaton fuqinë mistike që projekton njeriun në përditshmërinë e tij aktive. Ajo është një metaforë e shpirtit njerëzor, e thelbit dhe e rolit që luan çdo pjesë e shpirtit, një metaforë për artin dhe rrugët që çojnë drejt përsosjes shpirtërore. Ideja poetike e udhëtimit mistik të njeriut brenda vetes mishërohet përmes detajeve poetike të përzgjedhura, përmes simboleve dhe një gjuhe ezoterike7. Tek "Hambarët e shpirtit” sendërtohet artistikisht mesazhi: "Përsosmëria arrihet vetëm atëherë kur njeriu arrin të mposhtë të keqen-armiken e amëshimit, nëpërmjet udhëtimit brenda shpirtit të tij.

Ndërsa poezia "Kur koha të vdesë" sendërton figurën e kohës që rrjedh pa u ndalur:

7 Gjuhë që pasqyron gjendjen shpirtërore apo mendimet e njeriut dhe që synon të shpjegojë natyrën e ekzistencës (qenësisë) së tij. 


\title{
Albanon
}

Revistë kulturore

\section{Kur koha të vdesë}

\author{
Rrodhi lumi \\ nëpër shpatullat e ditës. \\ Në hinkën e natës \\ lumi u tha. \\ Dita u mbyt \\ në detin e natës pa ditë. \\ Nata dha shpirt \\ në detin e ditës pa natë. \\ Ka vdekur koha \\ në djepin e qiellit. \\ Cicërimat përkundnin folenë e zbrazët. \\ Engjëjt u bënë zogj, djepi lot u bë.
}

Poezitë "Shilarthi i fatit", "Dyert e fatit" dhe "Rruga mbi teh", janë gjithashtu lirika filozofike që i kushtohen enigmës mistike dhe të pazgjidhur të fatit të njeriut si dhe përsiatje poetike në përgjigje të pyetjes: A e bën njeriu fatin $\mathbf{e}$ vet apo vetëm e pëson atë?

Njerëzit bëjnë atë fat që është i paracaktuar për ta dhe këtu nuk ka kundërthënie, pasi është fjala për dy realitete thelbësisht të ndryshëm por që përbëjnë një unitet:

1. realiteti shpirtëror i përjetshëm, i kulluar, jashtëkohor. Ky realitet është gjithmonë i tillë, asgjë nuk ndodh në të, nuk ka lëvizje, as ndryshim ("devenir").

2. realiteti material, tridimensional në hapësirë dhe në kohë gjithnjë në lëvizje dhe ndryshe. Çdo gjë ndodh në këtë realitet, bëhet dhe zhbëhet për t'u ribërë përsëri. Poezia "Dyert e fatit" nis me vargjet:

\section{Dyert e fatit}

\author{
Mos trokit para se të bjerë muzgu. \\ Pa dëgjuar pëshpërimën e erës \\ mos trokit. \\ Këqyr skutat e shpirtit tënd. \\ Jo ngulthi... \\ Kur mugujt e epshit të jenë tharë,
}


hëna të ketë shtrydhur edhe pikën e fundit të gjirit

mbi supet e tua, vrugujt e gjakut të jenë shkulur me rrënjë

nga baltërat e kësaj bote....

Prozodia dhe struktura e këtyre tri vargjeve përcaktojnë kompozicionin e gjithë poezisë, pasi ato pasohen nga asosacione të fuqishme, të ngjizura me detaje tepër konkrete. Sistemi figurativ i metaforave, ndjesitë, idetë dhe përjetimet që vërshojnë irracionalisht sendërtojnë filozofinë e fatit dhe raportin e njeriut me të.

Meditimi poetik vjen si i tillë vetëm nën efektin e fjalës poetike. Po ta shohim simbolikën, përgjatë gjithë vëllimit "Dijetari i humbur" fjalori poetik është tipik i shprehjes subjektive: lumi, liqeni, zogjtë, drurët, shiu, lulet e portokajve, erëmimi i përlotur $i$ luleve, dielli i gremisur,syri i dhimbjes, shilarthi $i$ heshtjes, rrëpira e ditës etj.. Këto fjalë shenjojnë elemente të nostalgjisë, vuajtjes, dhimbjes, të cilat prodhojnë asocacione të gjendjes së shpirtit njerëzor, pra sendërtojnë tipin lirik, meditativ, ndjeshmërinë dhe përjetimin e subjektit. Në këtë mënyrë edhe peizazhi rikrijohet si sendërtim i subjektivitetit shpirtëror.

\section{Mërzi}

Shpirti u myk.

Nuhat sqetullat e mbrëmjes dhe shfryn furishëm.

Pikërron lëmashku i reve murrake.

Është larg kufiri i hënës së re,

Dergjet mesnata prapa shpinës.

Këmbët shkelin putrat e mesnatës.

Duart shtyjnë shtëllungat e reve.

Një fole e shpirtit qe çarë.

Vërshon mërzia gulfa gulfa.

I mbyti hidhërimi skutat e shpirtit.

Është larg kufiri i hënës së re...

(Tiranë, Shtëpia Botuese Naim Frashëri, 16 gusht 1985)

Edhe në poezinë e mësipërme, me titullin Mërzi, si në planin e poetikës, ashtu edhe në atë të refleksionit, karakteristikë është shfaqja e mendimit poetik. Thelbi i gjendjes së mërzisë shenjohet me simbolin e natës ndërkohë që i gjithë mendimi poetik lidhet me këtë figurë, me tërësinë kuptimore. 


\section{Albanon}

Revistë kulturore

Ajombart simbolikën e vetmisë, të mungesës së perspektivës, të dhimbjes prej të keqes që ka zaptuar çdo gjë, të mungesës së lirisë, kufirin e vdekjes.

Është larg kufiri i hënës së re,

Dergjet mesnata prapa shpinës.

E tërë poezia, ngrihet përmes fjalëve-ide: nata dhe shpirti. Fjala-figurë është boshti apo bërthama rreth së cilës ndërtohet në mënyrë të ngjeshur kuptimësia. Duke shfrytëzuar konotacionet dhe fuqinë shprehëse, nata shpreh një koncept të shenjuar poetik dhe rifunksionalizohet si përjetim lirik.

\section{Vdekja si përjetësi}

Nga tërësia poetike, e marrë në shqyrtim, tërheq vëmendje poema 99“Vetëm Zoti është i madb” (Allahu Ekber) që nuk ka qenë një zgjedhje e rastësishme e autorit, si poezia përmbyllëse e krejt vëllimit.

Në këtë poezi prej tragjizmit të vdekjes gjallon dhe rroket sublimja.Mjetet shprehëse poetike si:brerima e ditëve të vdekura, thershëm, zemërakull, mbretëria e të vdekurve, hapat ndjellakeqe të hidhërimit, afshi vetmisë, nëna e vdekur, pellgu i hidhur, shkretëtira e hirtë etj...ligjërojnë një vetëzbulim poetikofilozofik të vetë poetit. Vdekja i ka humbur përmasat e të zakonshmes, ajo hiperbolizohet në çdo dimension, duke pushtuar kohën dhe hapësirën:

Sot varrosa tim atë.

Tik-taku i orës së vjetër

mbledh fillin e ngatërruar

në brigjet e dy jetëve.

Brerima e ditëve të vdekura

thershëm,

zemërakull,

shuan prushin në qepallat e natës.

Isha i gjallë

në mbretërinë e të vdekurve.

Në mbretërinë e të gjallëve,

vdes i trishtë,

ringjallem pa shpresë

në çdo të rrahur të zemrës.

Rrënjëshkulur shtëpia e vjetër,

Buzëlidhur nata 
Mes zymtisë së drurëve,

Hapave ndjellakeqe të hidhërimit.

Hëna,

pas dritares,

përcëlloi qerpikët,

në afshin e vetmisë sime,

përgjon e mardhur

vetminë e vet.

Plaku shtegtoi.

Bebëzat e kaltra i mbuloi dheu sot.

Vetëm më la

Në pellgun e natës.

Pa gojë,

gishtprerë,

Thika e vockël mbi tryezë...

Ndante bukën me mua,

thërrmonte akullin e ditëve me të...

$S$ qava për tim atë.

I shtera lotët për nënën e vdekur.

Pellgu i hidhur

rreh brigjet e shpirtit,

thellë,

mbyturazi.

Gulçet e valëve më kumbojnë në veshë...

...Uturima e erës,

Shkretëtirae hirtë,

nën kupën e thyer të qiellit

zërat e përvajshëm të kalorësve.

"O djalë, nëna ka vdekur..."

Asgjë s'është shuar.

Asgjë s'ka vdekur.

Dy jetë dënesen shpresëhumbur

në honet e shpirtit tim.

Dhimbja e lashtë,

dhimbja e re

përcëllon buzët e mia.... 


\section{Albanon}

Revistë kulturore

Është një tragjizëm jetësor, një dialog i monologuar, ku uni poetik vetëzbulohet përmes rrëfimit.

Nga vargu iparë i thjeshtë: Sot varrosa tim atë-e në vargjet në vazhdim: Tik-taku i orës së vjetër/ mbledh fillin e ngatërruarl në brigjet e dy jetëve... dhimbja, dëshpërimi, trishtimi e çojnë subjektin poetik përtej një dhembjeje të zakonshme, në një lloj sublimiteti brenda vetë qenies. Ky kapërcim nga tragjizmi i vdekjes si humbje vetjake, shenjuar me detaje konkrete (Tiktaku $i$ orës së vjetër; Thika e vockël mbi tryezë...Ndante bukën me mua etj)dhe kontraste të fuqishme (në mbretërinë e të vdekurvel Në mbretërinë e të gjallëve; Dhimbja e lashtë, dhimbja e re etj)e deri tek ideja e përjetësisë në botën e pasosur bëhet shprehje e një arti poetik të arrirë. ${ }^{8}$

Vargjet shpalosin raportin e qenies me materien, botën me shpirtin, Zotin.

Vetmia është vetëm një gjendje fizike e zakonshme, që e bën poetin të përpëlitet midis dhembjes dhe mallit; ndarja me njeriun e dashur, babain është një marrëdhënie që dhemb dyfish, ajo ripërtërin më me forcë kujtimin e dhimbshëm për vdekjen e nënës:

Sonte jam po ai vocrraku i shkretëtirës

Me sy të ngufatur

Pas mjegullës së lotëve,

shigjetoj qiellin:

"O Zot, pse ma more nënën?"...

Tik-taku i orës

stërpik buzët e hënës

me gjakun e dy jetëve të mia.

Marrëdhënia e subjektit poetik me vdekjen paraqitet i përshkallëzuar: nga dhimbja, trishtimi dhe vetmia që shkakton vdekja e zakonshme biologjike, tokësore, kalohet në pranimin e natyrshëm të saj përmes besimit të patundur tek Zoti dhe përjetësimit në jetën e pasosur. Qenia poetike nuk ka dilema ekzistenciale:

Katër dhimbje,

katër dashuri,

mbi kuajt e qiellit kaluar.

Fytyrën Tënde adhurojnë O Zot!

8 Ibrahim Rugova, Strategjia e kuptimit, Shtëpia botuese. “F. Konica," Prishtinë, 2005, fq. 212 
Ndërsa në poezinë- testament -Kur të kem vdekur autori vë shenjën e barazimit midis artit dhe unit poetik, që shndërrohet në një qenie poetike. Kjo qenie nuk vdes por jeton në lëvizjen e jetës, të natyrës, sepse ky është fati i tij, dhuratë prej Zotit.

Kur tju kaplojë etja

për afshin e shpirtit tim,

hetoni njëpërnjë

fjalët që ju kam lënë.

Në kërcellin e çdo shkronje

rrjedh gjaku im.

Në folenë e çdo tingulli

do ringjallem për ju.....

Në një analizë tërësore të vëllimit “Dijetari i humbur”, mund të vërehet se nga poezitë e para që i përkasin një kohe më të hershme shkrimi, tek ato, të cilat mund të konsiderohen si të një faze më të vonë (pas viteve '85) vihet re një përpjekje e poetit për të hetuar në mënyrë të plotë harmoninë e gjuhës poetike, një kërkim drejt strukturave të reja, ku fuqia e fjalës poetike vjen duke u rritur hap pas hapi. Në një pjesë të tyre poeti ka lëvruar versetin-një varg i gjatë, i përdorur sidomos në poezinë franceze, pa rimë, i përshtashëm për të ndërthurur poetikën dhe prozën e jetës moderne.

Në përfundim, mund të themi se poezia e autorit Shpëtim Karaj dallohet për tiparet, sistemin konceptual dhe stukturën moderne të saj. Duke tentuar drejt të panjohurave të qenies, drejt metafizikës dhe trashedentales me mjetet e gjuhës poetike kjo poezi spikat një individualitet poetik të veçantë, befasues.

\section{Literatura e shfrytëzuar:}

Biblioteka Publike "Qemal Baholli" dhe historia e saj, përgatitur nga Drita H. Cankja, Manola Hatellari, Onufri, Tiranë, 2014

Dizionare della letteratura, Garzanti, “La Tipografia Varese S.P.A.”, 2003

Ibrahim Rugova, Strategjia e kuptimit, Shtëpia botuese "F. Konica', Prishtinë, 2005

Ilia Lëngu, "Vështrimi i Orfeut", artikuj dhe studimi, Argeta-LMG, Tiranë, 2007

Shpëtim Karaj, përmbledhja poetike "Dijetari $i$ humbur", dorëshkrim, Elbasan 2017 